\title{
ISLAMIC SCIENCE, NATURE AND HUMAN BEINGS: A Discussion on Ziauddin Sardar's Thoughts
}

\author{
Masthuriyah Sa'dan \\ Universitas Islam Negeri (UIN) Sunan Kalijaga, Yogyakarta \\ e-mail: masthuriyah.sadan@gmail.com
}

\begin{abstract}
Currently the development of western science has been very advanced. However, the development of western science only concerns towards big profits without any consideration about the side effects of science development itself. The western science has marginalized the aspects of metaphysics and theology so that the western science arises materialistic characteristics for human beings, ecological damage, and disharmonic situations between nature and human. This writing discussed Ziauddin Sardar thoughts about Islamic science applying descriptive analysis approach. In Sardar's thoughts, Muslim community must not follow western science; nevertheless, Muslim community may have Islamic science, having the Islamic characteristic and value. The characteristics of Islamic science cannot be separated from the ten parameters such as tawhïd, khiläfah, 'íbādah, 'ilm, halāl, harām, 'adl, zulm, istiṣlāḥ and diyā'.

Pada era sekarang ini perkembangan sains telah mengalami kemajuan yang sangat pesat. Namun kemajuan sains hanya mengambil keuntungan sebesarbesarnya, tanpa memikirkan dampak dari perkembangan sains itu sendiri. Sains telah memarginalkan sisi metafisika dan teologi sehingga sains Barat menimbulkan sifat materialistis bagi manusia, kerusakan ekologi, dan ketidakharmonisan antara alam dan manusia. Tulisan ini mengkaji pemikiran Ziauddin Sardar tentang sains Islam dengan pendekatan analisis deskriptif. Dalam pandangan Sardar, masyarakat Muslim tidak harus mengekor sains Barat, akan tetapi masyarakat Muslim bisa memiliki sains sebagai karakteristik sains yang bercorak dan bernilai Islam yakni sains Islam. Adapun karaketeristik sains Islam tidak lepas dari sepuluh parameter yang meliputi tawhịd, khilāfah, 'ibādah, 'ilm, hạāal, harām, 'adl, ẓulm, istị̂lāḥ dan diyā'.
\end{abstract}

Keywords: Islamic science, Ziauddin Sardar, Western science, ten parameters 


\section{A. Pendahuluan}

Sains dianggap sebagai ajang eksploitasi untuk menghasilkan keuntungan yang sebesar-besarnya tanpa memikirkan masa depan bumi, manusia dan ekosistem yang ada di dalamnya. Dampak terbesar adalah terjadinya "krisis global", sebagai akibat dari maraknya pembangunan rumah kaca, sehingga lapisan ozon mulai menipis. Pabrik industri menjamur di mana-mana, sehingga limbahnya mengakibatkan polusi air limbah dan berefek pada air sungai yang tidak lagi bersih tapi keruh, hitam dan bau. Kendaraan yang memadati jalan raya sehingga menimbulkan polusi udara yang mengganggu pernafasan dan paru-paru, penebangan pohon di hutan sebagai akibat pembangunan besarbesaran mengakibatkan banjir dan tanah longsor. Akibatnya, penyakit modern bermunculan di mana-mana, terkurasnya sumber energi dan sumber daya alam di perut bumi, ledakan penduduk dan berbagai masalah mengenai hutan dan gunung.

Sains digunakan untuk mengejar keuntungan dan jumlah produksi, untuk pengembangan militer dan perlengkapan-perlengkapan perang, serta untuk dominasi ras manusia terhadap ras manusia lainya (kolonialisme). Bahkan kepada alam, dominasi alam merupakan nilai tertinggi dalam sains, sehingga semuanya dikorbankan di atas altar sains.

Dalam keadaan yang demikian, Roszak menggambarkan bahwa sains modern sebagai bentuk makhluk yang sangat menakutkan karena berwajah putus asa dan berkomestik keputusasaan spiritual. Lebih lanjut, Roszak menggambarkan sains modern sebagai spesies yang sangat menakutkan. ${ }^{1}$ Karena adanya dampak buruk dari sains modern inilah, masyarakat Barat mengkritik "Barat" beserta prospek masa depan peradaban Barat. Di saat-saat seperti inilah, Sardar menawarkan gagasannya untuk membuat sebuah alternatif Islam yang kokoh terhadap imperialisme Barat dengan skala rekonstruksi peradabannya. Sardar mengusulkan sains yang didasarkan pada agama dengan

\footnotetext{
${ }^{1}$ Maka Roszak mengusulkan "gnosis" sebagai pengganti sah bagi pengetahuan ilmiah, dan mengutip Paull Tillich bahwa gnosis sebagai knowledge by participation (pengetahuan dengan partisipasi). Gnosis bukanlah pengetahuan yang dihasilkan oleh riset analitis dan sintetis, akan tetapi gnosis adalah pengetahuan mengenai persatuan dan keselamatan. Gnosis merupakan pengetahuan eksistensial yang berbeda sekali dengan pengetahuan ilmiah. Ziauddin Sardar, Sains, Teknologi dan Pembangunan di Dunia Islam, terj. Rahmani Astuti, (Bandung: Mizan, 1989), h. 28.
} 
memulai himbauan kritik atas sains modern. Sardar mempersoalkan kebebasnilaian sains, menekankan merusaknya beberapa produknya, dan menunjukkan bahwa teknologi modern telah menjurus kepada dehumanisasi dan robotisasi masyarakat manusia.

Ironisnya, ilmuwan-ilmuwan Muslim selalu mengelak acapkali diskusi mengenai sains, teknologi dan nilai-nilai dimulai. Malah dari mereka hanya sedikit yang menunjukkan perhatian pada kritik sains Barat. Sardar menganggap bahwa sikap ilmuwan-ilmuwan Muslim yang seperti itu menunjukkan bahwa mereka telah lari dari jalur sains yang sebenarnya, menyangkal teknologi modern dan mencerabut para ilmuwan dari hasil-hasil sains dan teknologi yang hanya menguntungkan peradaban Barat. ${ }^{2}$

Padahal ilmuwan sains Muslim klasik seperti al-Razi, al-Biruni dan Ibn Haitsam menggunakan sains dengan formulasi kerangka nilai-nilai al-Qur'an yakni paradigma sains Islam dengan konsep tawhïd, khilāfah dan 'ibādah. Inilah kegelisahan Sardar, bahwa ilmuwan-ilmuwan Muslim kontemporer tidak memiliki kesadaran kolektif untuk merealisasikan sains Islam seperti yang telah dilakukan oleh para pendahulu-pendahulu. Akan tetapi ilmuwan-ilmuwan Muslim kontemporer hanya mencatat kembali prestasi-prestasi ilmuwan Muslim klasik, yang dalam bahasa anekdot Sardar, ilmuwan-ilmuwan Muslim kontemporer hanya "mengumpulkan perangko". ${ }^{3}$ Tulisan ini mengkaji pemikiran Sardar seorang intelektual sains Muslim asal Pakistan tentang sains Islam berikut kontribusinya terhadap perkembangan ilmu pengetahuan.

\section{B. Sketsa Hidup Ziauddin Sardar}

Ziauddin Sardar adalah seorang intelektual Muslim yang juga seorang penulis Islam progresif dan penulis kajian pemikiran Islam kontemporer, seorang saintis dan kritikus budaya. Sardar dilahirkan pada tahun 1951 di Punjab Pakistan, besar di Hackneyh, kawasan timur London dan bermukim di Inggris. ${ }^{4}$

2Ziauddin Sardar, Jihad Intelektual: Merumuskan Parameter-parameter Sains Islam, (Surabaya: Risalah Gusti, t.th.), h. 122.

3Ziauddin Sardar, Jihad Intelektual ...., h.129.

${ }^{4}$ Ode Abdurrahman, "Sardar dan Rekonstruksi Peradaban Muslim", http://infolepas. blogspot. com/2006/05/sardar-dan-rekonstruksi-peradaban.html, diakses pada tanggal 10 Agustus 2015. 
Di Inggris inilah Sardar tumbuh dan merasa termarginalisasi serta merasa mendapat ketidakadilan sosial, baik secara sosial maupun psikologis. Tekanan yang dialami Sardar ternyata juga dialami oleh Muslim minoritas di Inggris. Itu semua terjadi, karena adanya kekhawatiran orang-orang Inggris terhadap meludaknya masyarakat Muslim di Inggris. Ada streotipe lama yang bersemayam dalam benak diri masyarakat Inggris, bahwa umat Muslim ibarat virus herpes yang tidak dapat disembuhkan. Misal, ketika Muslim Inggris mengusulkan agar sekolah Islam didirikan, maka usulan itu dianggap oleh masyarakat Inggris sebagai sebuah ancaman peradaban Barat. Konsekuensinya, Muslim Inggris dianggap sebagai duri yang harus dihilangkan, dalam ketegangan sosial seperti inilah, Sardar tumbuh besar di Inggris. ${ }^{5}$

Di saat yang bersamaan pula, Sardar melihat komunitas-komunitas Muslim terjebak dalam interpretasi-interpretasi Islam di masa kejayaan silam. Tradisi Islam yang dinamis menjadi beku, dan selama beberapa abad Islam tidak tersentuh oleh penafsiran baru. Tampaknya umat Islam tidak mau untuk berkubang dalam aktivitas penafsiran yang merespon perkembangan zaman. Di sisi lain, Sardar melihat kelompok Islam modernis terjebak ke dalam pemujaan modernitas yang berlebihan. Kedua mainstream Islam ini, tradisional dan modernis, melihat dunia dengan lensa hitam dan putih yang atomistik, dan dari kondisi sosial yang seperti inilah, Sardar membuat sintesis baru dengan menawarkan visi-visi tentang masyarakat Muslim masa depan. ${ }^{6}$

Di lihat dari pengalaman dunia kerja, Sardar pernah bekerja sebagai jurnalis sains untuk alam dan New Scientist dan sebagai reporter televisi untuk London Weekend Television. Sardar juga sebagai kolumnis di New Statesmen selama beberapa tahun dan pernah menjabat sebagai Komisaris untuk Kesetaraan dan Komisi Hak Asasi Manusia (HAM) dan sebagai anggota interim Forum Keamanan Nasional. Sebagai seorang penulis, Sardar telah menerbitkan lebih dari 45 buku, di antaranya adalah: Masa Depan Peradaban Islam (1979), Futures Islam: The Shape of Ideas to Come (1985).

\footnotetext{
${ }^{5}$ Rusli, "Islam dan Lingkungan Hidup: Meneropong Pemikiran Ziauddin Sardar", Majalah Hermeneia Pasca UIN Sunan Kalijaga, Vol. 3. No. 2, Juli-Desember 2004, h. 177.

${ }^{6}$ Sisntesis baru yang Sardar gagas tidak terlepas dari sumber-sumber pemikiran Sardar yang terinspirasi oleh pemikiran Thomas Khun dengan teori "Paradigma"nya dan Paul Feyeberand dengan teori "anarkis" sainsnya. Rusli, "Islam dan Lingkungan Hidup: Meneropong Pemikiran Ziauddin Sardar", Majalah Hermeneia Pasca UIN Sunan Kalijaga, Vol. 3. No. 2, Juli-Desember 2004, h. 178.
} 
Sardar juga memelopori diskusi pada ilmu pengetahuan dalam masyarakat Muslim, dengan serangkaian artikel di Alam dan New Scientist dan sejumlah buku, termasuk Sains, Teknologi dan Pengembangan di Dunia Muslim (1977), The Touch of Midas: Sains, Nilai dan lingkungan dalam Islam dan Barat (1982), yang dipandang sebagai karya manis, The Revenge of Athena: Sains, Eksploitasi dan Dunia Ketiga (1988) dan Explorations in Ilmu Islam (1989). Postmodernisme dan Lainnya (1998) dan Mengapa Orang Benci Amerika? (2002) menjadi bestseller internasional. Ziauddin Sardar dalam dua volume biografi dan perjalanan, Desperately Seeking Paradise: Perjalanan Seorang Muslim Skeptis (2004) dan Inggris Balti: Perjalanan Provokatif Melalui Asian Inggris (2008) telah mendapat pengakuan luas. Ia juga telah menulis sejumlah panduan belajar dalam seri Memperkenalkan, termasuk buku terlaris internasional Memperkenalkan Islam dan Memperkenalkan Chaos. Dua koleksi tulisan-tulisannya yang tersedia: Islam, Postmodernisme dan Futures Lain: a Ziauddin Sardar Reader (2003) dan Bagaimana Apakah Anda Tahu? Reading Ziauddin Sardar tentang Islam, Sains dan Hubungan Kebudayaan (2006), 7 dan berbagai tulisan Sardar lainnya.

\section{Sains Islam: Kajian Teori}

Sains Islam berupaya mengkaji semua aspek alam yang beraneka ragam dari sudut pandang yang menyatu dan terpadu. Tujuan dari sains Islam adalah untuk menampakkan kepada manusia akan adanya kesatuan alam semesta, yakni kesalinghubungan seluruh bagian dan aspeknya. ${ }^{8}$

Armahedi Mahzar mengatakan bahwa paradigma sains Islam adalah bagian dari kegiatan transformatif manusia terhadap lingkungannya dalam rangka mensyukuri nikmat karunia Allah. Mahzar melanjutkan bahwa teknologi sebagai bentuk penerapan ilmu. Jadi dalam sains Islam, teknologi tidak dapat dipisahkan dari nilai-nilai etika yang berdasarkan nilai-nilai sosial kemanusiaan, tidak bisa dilepaskan dari nilai-nilai kultural kemasyarakatan, nilai-nilai universal kealaman, nilai-nilai transendental keagamaan dan nilai-nilai instrumental keteknikan. ${ }^{9}$

\footnotetext{
7Tim Redaksi, “Biograpy”, http://ziauddinsardar.com/ziauddin-sardar-biography/, diakses pada tanggal 10 Agustus 2015.

8 Osman Bakar, Tauhid dan Sains: Esai-esai tentang Sejarah dan Filsafat Sains Islam, terj. Yuliani Liputo, (Bandung: Pustaka Hidayah, 1994), h. 76.

${ }^{9}$ Armahedi Mahzar, Revolusi Integralisme Islam: Merumuskan Paradigma Sains dan Teknologi Islami, (Bandung: Mizan,2004), h. 224-225.
} 
Guru besar fisika di Universitas Teknologi Syarif Iran Golshani mengatakan bahwa ${ }^{10}$ sains Islam merupakan perbuatan atau lebih tepatnya kajian yang tidak tercela, buktinya bisa dilihat dari beberapa Hadits Nabi dan ayat-ayat alQur'an.11 Para cendekiawan Islam klasik menggunakan dasar-dasar tawhìd dalam rangka merealisasikan hasil ilmiahnya sehingga temuan-temuan tersebut membentuk peradaban Islam di Kordoba, Spanyol. Kemudian, Golshani menambahkan bahwa pelanjut cendekiawan Muslim klasik, kita-kita inilah yang melanjutkan dan menghidupkan kembali semangat ilmiah untuk membentuk kembali cabang-cabang ilmu dan memanfaatkannya demi kemajuan peradaban Islam. Tidak ada istilah dikotomi ilmu bagi cendekiawan Muslim klasik, ilmu-ilmu agama dan ilmu-ilmu kealaman memiliki tujuan yang sama yakni membawa manusia kepada Tuhan. ${ }^{12}$

Golshani juga mengatakan bahwa al-Qur'an memberi gelar kepada manusia sebagai khaliffah di bumi. ${ }^{13}$ Ketika pemberian gelar itu sudah disandang oleh manusia, maka Tuhan menganugerahkan manusia akal, melalui penciptaan manusia dan lingkungan alam semesta telah diberi keharmonisan yang indah dan selaras sehingga manusia dapat memenuhi kebutuhankebutuhan hidupnya. Dengan demikian, sains dan teknologi adalah untuk keselarasan manusia dan alam semesta, menjaga keharmonisan manusia dan semua ciptaan Tuhan. Sebagaimana firman Allah:

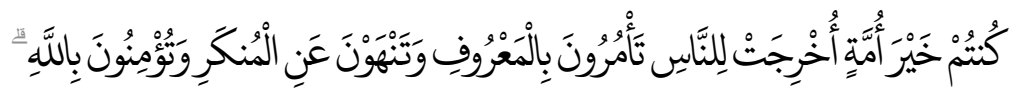

\footnotetext{
10Uraian ini dapat di lihat di Mehdi Golshani, Filsafat Sains Menurut al-Qur'an, terj. Agus Effendi, (Bandung: Mizan, 2003), h. 47-49.

11Dalam beberapa Hadits Nabi disebutkan: "Barang siapa menempuh jalan untuk mencari ilmu, maka Allah akan memudahkan jalannya ke surga”. "Mencari ilmu itu wajib bagi setiap muslim”. "Carilah ilmu sejak dari buaian hingga ke liang lahat", dan Hadits Nabi "Para ulama' itu adalah pewaris para Nabi". Adapun dalam al-Qur'an disebutkan: "Katakanlah: adakah mereka yang mengetahui dengan mereka yang tidak mengetahui itu sama?" (QS. Al-Zumar: 9). Begitu pula firman Allah....'...dan di antara kalian ada yang dikembalikan kepada bagian terjelek kehidupan, sehingga setelah memiliki ilmu dia tidak mengetahui sesuatu pun..." (QS. al-Nahl:70). Lihat al-Qur'an dan Terjemahnya, (Bandung: Syaamila Cipta Media, 2005).

${ }^{12}$ Mehdi Golshani, Filsafat Sains Menurut al-Qur'an, h. 49.

13"Ingatlah ketika Tuhanmu berfirman kepada para malaikat: "Sesungguhnya Aku hendak menjadikan seorang khalifah di muka bumi" (QS. al-Baqarah [2]:30) dan "Sesungguhnya kami telah menempatkan kamu sekalian di muka bumi dan Kami ciptakan bagimu (sumber) kehidupan...." (QS. alA'raf [7]: 10). Departemen Agama RI, al-Qư'an dan Terjemahannya, (Bandung: Syaamila Cipta Media, 2005).
} 


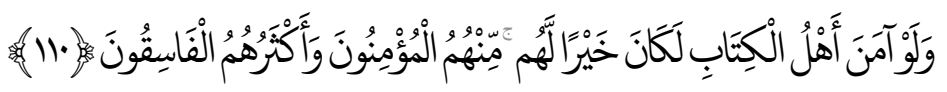

"Kamu adalah umat yang terbaik yang dilahirkan untuk manusia, menyuruh kepada yang ma'ruf, dan mencegah dari yang munkar, dan beriman kepada Allah. sekiranya ahli Kitab beriman, tentulah itu lebih baik bagi mereka, di antara mereka ada yang beriman, dan kebanyakan mereka adalah orangorang yang fasik." 14

Menurut Hoodbhoy, inti sains Islam adalah bersumber dari hasil kompromi ulama ortodoks dengan para penguasa Pemerintah Pakistan dengan mengatasnamakan Islam. Padahal kedua kubu tersebut memiliki kepentingan masingmasing. Bagi ulama, sains Islam memungkinkan perluasan dominasi hukum Islam ke dalam fenomena alami. Dengan demikian, sains Islam menjadi alat untuk berjuang menghadapi tantangan berupa dominasi sains sekuler yang terus meningkat. Bagi penguasa Pemerintah Pakistan, sains Islam menjadi bagian dari manipulasi keagamaan. Lebih lanjut Hoodbhoy mengatakan bahwa jika Pemerintah tidak mengucurkan dana, niscaya tidak akan lahir sains Islam. ${ }^{15}$

\section{Sains Islam Perspektif Ziauddin Sardar}

Seperti yang telah dikatakan dimuka, bahwa sains modern bagi Barat adalah segala-galanya, semua boleh dikorbankan demi dan atas nama sains termasuk manusia sekalipun, dan ini berbeda dengan sains Islam. Islam memiliki perspektif yang berbeda, pencarian ilmu pengetahuan 'ilm hanya bermakna jika ilmu pengetahuan dicari berdasar pada pandangan dunia Islam itu sendiri, terutama Islam menekankan pencarian karunia Allah dalam setiap ciptaan-Nya. Inilah yang membedakan sains Barat dan sains Islam. Jika sains Barat tunduk pada nilai-nilai kebudayaan dan peradaban Barat maka sains Islam mengembangkan nilai-nilai pandangan dunia Islam. ${ }^{16}$

Sardar memandang bahwa sains sebagai serangkaian aktivitas manusia. Akan tetapi pandangan yang seperti ini menurut Sardar banyak orang yang menolaknya, karena bagi sebagian orang sains adalah semata-mata sebuah metode tepatnya sebuah metodologi objektif untuk mengukuhkan fakta-fakta

\footnotetext{
${ }^{14}$ QS. Ali Imran [3]: 110.

15Pervez Hoodbhoy, Islam dan Sains: Pertarungan Menegakkan Rasionalitas, terj. Luqman, (Bandung: Pustaka, 1997), h. 190.

16Ziauddin Sardar, Jihad Intelektual ..., h. 62.
} 
yang dapat dibuktikan. Sebagian orang yang lain mengatakan bahwa sains adalah pengetahuan publik yang semakin besar dan koheren akibat penerapan metododologi yang kumulatif. Sardar sendiri memandang sains sebagai kombinasi yang kompleks dari ketiga buah pandangan-pandangan di atas. Artinya, aspek sains seharusnya berorientasi kepada nilai-nilai dan seluruh sains harus merupakan aktivitas kultural yakni sebuah aktivitas yang dibentuk oleh pandangan duniawi sang pelaku sains. ${ }^{17}$

Terdapat beraneka ragam pendapat cendekiawan Muslim tentang sains Islam, dan Sardar menyajikan sains Islam dalam bentuk berkesesuain dengan al-Qur'an. Apa yang telah Sardar gagas tentang sains Islam dengan orang-orang yang sealiran dengannya dalam mengemukakan ide sains dengan berdasar pada al-Qur'an dan Hadits disebut dengan kelompok Bucailis; yakni kelompok sains Islam yang sama idenya dengan Sardar, dengan berdasarkan pada Murice Bucaile-seorang dokter ahli embriologi berkebangsaan Prancis. ${ }^{18}$

Sardar mendefinisikan sains sebagai sarana pemecah masalah (problem solving) ${ }_{1}^{19}$ karena tanpa sains suatu peradaban tidak akan dapat mempertahankan struktur-struktur politik dan sosial atau untuk memenuhi kebutuhankebutuhan dasar rakyat dan budayanya. Begitu besar pengaruh sains sehingga sains bisa membentuk lingkungan fisik, intelektual dan budaya serta memajukan cara produksi ekonomis yang dipilih oleh suatu peradaban. Pendek kata, menurut Sardar, sains adalah sarana untuk mencetak suatu peradaban.

Sardar mengatakan bahwa ukuran-ukuran untuk membedakan antara sains Barat dan sains Islam paling sedikit terdapat 15 point yang menjadi perbandingan antara ukuran sains barat dan sains Islam di antaranya adalah:20 untuk ukuran sains Barat memiliki berbagai kriteria antara lain: (1) Percaya pada rasionalitas. (2) Sains untuk sains. (3) Satu-satunya metode untuk mengetahui realitas. (4) Netralitas emosional sebagai prasayarat kunci menggapai rasionalitas. (5) Tidak memihak, seorang ilmuwan harus peduli hanya pada produk pengetahuan baru dan akibat-akibat penggunaan-penggunaanya.

\footnotetext{
17 Ziauddin Sardar, Sains, Teknologi, dan Pembangunan di Dunia Islam, h. 17.

18 Ach. Maimun Syamsuddin, Integrasi Multidimensi Agama dan Sains: Analisis Sains Islam al-Attas dan Mehdi Golshani, (Yogyakarta: IRCiSod, 2012), h. 21-22.

19Ziauddin Sardar, Masa Depan Islam, terj. Rahmani Astuti,(Bandung: Pustaka, 1987), h.. 161.

20Ziauddin Sardar, Exploration in Islamic Sciense, (London: Mansel Publishing Limited, 1989), h. 9597.
} 
(6) Tidak adanya bias, validitas pernyataan sains hanya tergantung pada bukti penerapanya dan bukan pada ilmuwan yang menjalankannya. (7) Penggantungan pendapat, pernyataan-pernyataan sains hanya dibuat atas dasar bukti yang meyakinkan.

Selanjutnya, (8) Reduksionisme, cara yang dominan untuk mencapai kemajuan sains. (9) Fragmentasi, sains adalah sebuah aktivitas yang terlalu rumit, karenanya harus dibagi kedalam disiplin-disiplin dan subdisiplinsubdisiplin. (10) Universalisme, meski sains itu universal, namun buahnya hanya bagi mereka yang mampu membelinya, dengan demikian bersifat memihak. (11) Individualisme, meyakini bahwa ilmu harus menjaga jarak dengan permasalahan sosial, politik dan ideologis. (12) Netralitas, sains adalah netral, apakah ia baik ataukah ia buruk. (13) Loyalitas kelompok, hasil pengetahuan baru melalui penelitian marupakan aktivitas terpenting dan perlu di junjung tinggi. (14) Kebebasan absolut, setiap pengekangan atau penguasaan penelitian sains harus dilawan. (15) Tujuan membenarkan sarana. Karena penelitian ilmiah adalah mulia dan penting bagi kesejahteraan umat manusia, setiap sarana termasuk pemanfaatan hewan hidup, kehidupan manusia dan janin dibenarkan demi penelitian sains.

Sedangkan ukuran sains Islam antara lain: (1) Percaya kepada wahyu. (2) Sains adalah sarana untuk mendapatkan keridhoan Allah dan merupakan bentuk ibadah yang memiliki fungsi spiritual dan sosial. (3) Banyak metode berlandaskan akal dan wahyu, baik objektif maupun subjektif, semuanya sama-sama valid. (4) Komitmen emosional sangat penting untuk mengangkat usaha-usaha sains spiritual maupun sosial. (5) Pemihakan pada kebanaran, yaitu apabila sains merupakan salah satu bentuk ibadah, maka seorang ilmuwan harus peduli pada akibat-akibat penemuanya sebagaimana juga terhadap hasil-hasilnya. Ibadah adalah satu tindakan moral dan dan konekuensinya harus baik secara moral, dan mencegah ilmuwan agar jangan menjadi agen yang tidak bermoral.

Selanjutnya, (6) Adanya subjektivitas, arah sains dibentuk oleh kriteria subjektivitas, validitas sebuah pernyataan sains bergantung baik pada buktibukti pelaksanaanya maupun pada tujuan dan pandangan orang yang menjalankanya. Pengakuan pilihan-pilihan subjektif pada penekanan dan arah sains mengahruskan ilmuwan mengahragai batas-batasnya. (7) Menguji pendapat, pernyataan-pernyataan sains selalu dibuat atas dasar bukti yang tidak meyakinkan. Menjadi seorang ilmuwan harus menjadi seorang pakar, juga 
mengambil keputusan moral, atas dasar bukti yang tidak meyakinkan sehingga ketika bukti yang meyakinkan dikumpulkan baraangkali terlambat untuk mengantisipasi akibat-akibat destruktif dari aktivitas seseorang. (8) Sintesis, cara yang dominan dalam meningkatkan kemajuan sains, termasuk sintesis sains dan nilai-nilai. (9) Holistik, sains adalah sebuah aktivitas yang terlalu rumit yang dibagi kedalam lapisan yang sangat kecil, yang juga merupakan pemahaman interdisipliner dan holistik. (10) Universalisme, buah sains adalah untuk seluruh umat manusia, ilmu pengetahuan dan kebijaksanaan tidak dapat ditukar atau diperjualbelikan, hal itu merupakan sesuatu yang tidak bermoral.

Kemudian, (11) Orientasi masyarakat. Penggalian sains adalah kewajiban masyarakat (farḍu kifāyah), baik ilmuwan maupun masyarakat memiliki hak dan kewajiban yang meyakini adanya interdependensi antara keduanya. (12) Orientasi nilai, sains seperti halnya semua aktivitas manusia adalah sarat nilai, ia bisa baik atau buruk, halal atau haram, sains yang menjadi benih perang adalah jahat. (13) Loyalitas kepada Tuhan dan makhluknya, hasil pengetahuan baru merupakan cara memahami ayat-ayat Tuhan dan harus diarahkan untuk meningkatkan kualitas ciptanya, baik manusia hutan dan lingkungan. Tuhanlah yang menyediakan legitimasi bagi usaha ini dan oleh karena itu, harus didukung sebagai tindakan umum dan bukan merupakan usaha golongan tertentu. (14) Manajemen sains merupakan sumber yang tidak terhingga nilainya, sains tidak boleh disia-siakan dan digunakan untuk tindak kejahatan, ia harus dikelola dan direncanakan dengan baik dan harus dipaksa oleh nilai etika dan moral. (15) Tujuan tidak membenarkan sarana, tidak ada perbedaan antara tujuan dan sarana sains, kedua-duanya semestinya diperbolehkan (halāl), yakni dalam batas-batas etika dan moral.

Maksud dari sains Islam adalah sains yang proses-proses dan metodologimetodologinya memasukkan semangat nilai-nilai Islam, menjunjung tinggi citacita dari pandangan dunia Islam seperti persaudaraan, keadilan sosial, pemanfaatan sumber daya alam secukupnya, mengingatkan manusia akan kedudukannya sebagai khalifah Tuhan dan meningkatkan kesadaran ruhani dan memenuhi kebutuhan-kebutuhan masyarakat Muslim. Sains Islam tidak lebih adalah merupakan aplikasi nilai-nilai, kebudayaan dan tradisi intelektual Islam. ${ }^{21}$

21Ziauddin Sardar, Masa Depan Islam, h. 176. 
Dalam mengusung gagasan sains Islam, Sardar berpatokan pada argumen Nasr dalam bukunya Islamic Science: an Illustrated Study ${ }^{22}$ bahwa Islam mempunyai suatu identitas tersendiri dan berusaha menonjolkan ciri Islaminya yang unik. Akan tetapi menurut Sardar, Nasr lebih condong menampilkan metafisika dan tasawufnya dalam aspek-aspek sains Islam sehingga mengabaikan aspek-aspek kuantitatif dalam sains Islam.

Untuk merealisasikan sains Islam, Sardar beserta sarjana-sarjana Muslim dan Barat mengadakan konferensi internasional "Islam and the West" di Stockholm pada 24-27 September 1981 dan bersepakat bahwa parameterparameter dari sains Islam harus didasarkan pada suatu kerangka nilai yang merupakan karakteristik-karakteristik dasar kebudayaan Islam. Terdapat 10 konsep yang diidentifikasi sebagai parameter-parameter sains Islam dalam seminar tersebut yang meliputi: tawhìd (keesaaan Allah), khalïfah (wali Allah), 'ibādah, 'ilm (pengetahuan), ḥalāl (hal-hal yang dibolehkan), harām (hal-hal yang dilarang), 'adl (keadilan sosial), zulm (tirani), istiṣlāḥ (kepentingan umum), dan diyā' (pemborosan). ${ }^{23}$

Konsep tawhìd yang bermakna keesaan Tuhan, ditegaskan menjadi kesatuan umat manusia, kesatuan antara umat manusia dan alam, kesatuan antara ilmu pengetahuan dan nilai. Menjadikan konsep tawhīd sebagai esensi pemikiran dan prilaku sosial Islam. Maka dari tawhīd, akan muncullah khilāfah; bahwa sejatinya manusia tidak bisa independen dari Tuhan, akan tetapi manusia akan dimintai pertanggungjawabanya kelak mengenai apa yang telah ia lakukan selama hidup di dunia, baik itu menyangkut peran sebagai ilmuwan dalam kegiatan-kegiatan ilmiahnya. Jika seorang saintis merasa sebagai perwakilan Tuhan (khaliffah), maka dia akan sadar diri, bahwa ia tidak memiliki hak eksklusif dan preoregatif dengan keilmuwanya yang otoriter terhadap lingkungan, alam dan manusia. Akan tetapi seorang saintis akan menjaga keselarasan dan keharmonisannya di muka bumi, sehingga tidak akan ada istilah manusia yang menaklukkan bumi (eksploitasi dan dominasi terhadap alam), adanya manusia menjaga kelestarian bumi. Kesadaran tawhīd dan khilāfah muncul, manakala saintis tersebut melakukan kewajiban kontemplasi ('ibā-

\footnotetext{
22Ziauddin Sardar, Masa Depan Islam, h. 179.

23Ziauddin Sardar, Jihad Intelektual..., h. 126. Bandingkan dengan, Ziauddin Sardar, Masa Depan Islam, h. 181.
} 
dah). Sebagaimana yang dikatakan Sardar, bahwa ibadah menjadi faktor yang mengintegrasikan kegiatan ilmiah dengan sistem nilai-nilai Islam.

Sedangkan 'ilm (pengetahuan) dibagi menjadi dua kategori, diantaranya adalah; pengetahuan yang diwahyukan yang menyangkut etika dan moral dan pengetahuan yang tidak diwahyukan, pengetahuan yang tidak diwahyukan inilah yang menjadi kewajiban bagi umat Islam untuk mencarinya di dalam kerangka ibadah kepada Allah. Pengetahuan yang tidak diwahyukan ini dibagi menjadi dua yakni fardu 'ayn; yang esensial bagi individu untuk dicari sebagai pertahanan etika dan moral dan pengetahuan yang farḍ kifāyah; pengetahuan yang dibutuhkan untuk keberlangsungan hidup masyarakat secara keseluruhan.

Bagi Sardar, jika pengetahuan sains untuk kepentingan dan keberlangsungan hidup masyarakat, maka pengetahuan sains tersebut bernilai ibadah. Jadi tidak ada istilah "sains untuk sains" adanya, sains untuk ummah. Apabila sains bermanfaat baik bagi individu, masyarakat dan lingkungan, maka sains tersebut adalah hạlāl, dan jika hạlāl, maka akan menuju pada keadilan sosial ('adl), akan tetapi jika sains tersebut berbahaya baik bagi individu, masyarakat maupun lingkungan, menimbulkan alienasi dan dehumanisasi, maka sains tersebut adalah ḥarām, dan akan menimbulkan malapetaka (zalim).

Sains yang mengancam pada kehidupan dan menimbulkan malapetaka (zalim) maka akan mengakibatkan terkurasnya Sumber Daya Alam (SDA), merosotnya Sumber Daya Manusia (SDM) dan akan berdampak pada buruknya ekologi, sains yang demikian dikategorikan sebagai sains yang boros (diya'). Akan tetapi jika sains tersebut menjaga kelestarian alam dan makhluk hidup di dalamnya, dan meningkatkan keadilan sosial ('adl), maka sains tersebut dikategorikan sebagai sains yang istiṣlāh (sains yang berorientasi pada kepentingan umum).

Terdapat sepuluh parameter sains Islam perspektif Sardar, untuk mempermudah sketsa sains Islam menurut Sardar, lihatlah gambar diagram berikut. Melalui sepuluh parameter sains Islam tersebut, di bagian akhir tulisan Sardar, ia tidak serta merta menolak sains Barat. Menurutnya, sains Barat masih ada yang masuk kriteria parameter sains Islam seperti pengelolaan sumber daya energi yang tepat guna, penelitian kedokteran untuk mengurangi sakit dan menyembuhkan penyakit, pengembangan botani untuk menanggulangi kelaparan dunia dan berbagai usaha-usaha ilmiah lainnya yang ramah lingkung- 
an. Akan tetapi, perlu digarisbawahi jika sains tersebut menimbulkan kerusakan alam (ekologi), manusia, hewan dan tumbuh-tumbuhan maka sains tersebut tidak 'adl dan tentunya zālim, inilah yang tidak diinginkan oleh Sardar dalam gagasanya di sains Islam. ${ }^{24}$

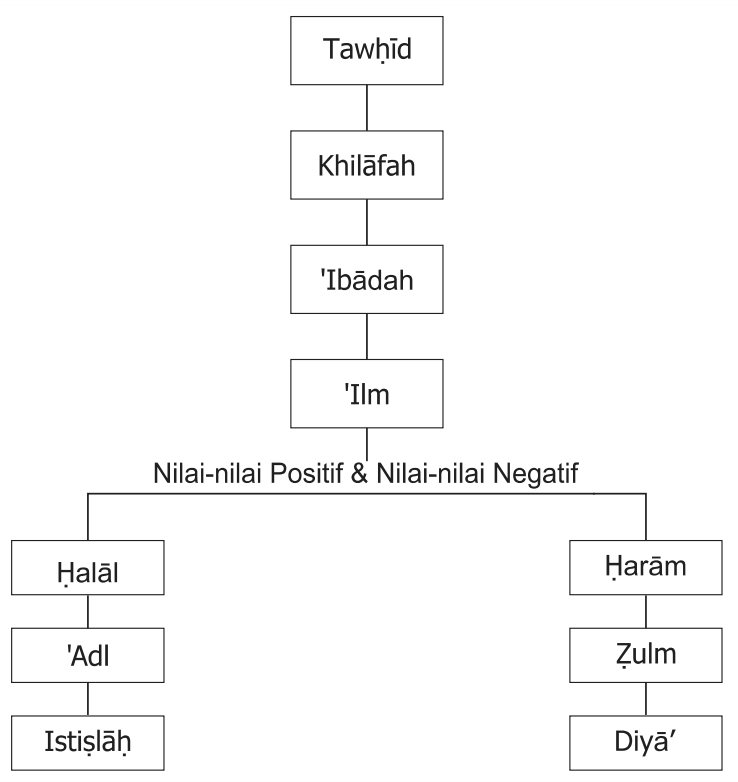

Secara sederhana, yang diinginkan Sardar dalam teori sains Islam adalah bagaimana sains baik itu Barat maupun Islam memberikan konstribusi terhadap keberlangsungan alam dan kesejahteraan manusia. Artinya, sains tersebut memanusiakan manusia dan mengalamkan alam, bukannya menjadikan sains sebagai ancaman keberlangungan hidup alam dan manusia. Oleh sebab itu, Sardar menekankan pentingnya tawhīd (mengesakan Allah) baik dalam agama maupun sains.

\section{E. Kontribusi Sains Islam terhadap Ilmu Pengetahuan}

Usaha Sardar untuk mengembalikan ilmu baik ilmu agama maupun ilmu pengetahuan (science) ke muara Islam dengan berdasar pada nilai-nilai alQur'an dan Hadits layak untuk kita apresiasikan. Betul memang, cendekiawan

24Ziauddin Sardar, Masa Depan Islam, h. 130. 
Muslim klasik seperti al-Biruni, Ibnu Haitsam dan lain-lain, dalam sains menggunakan kerangka berpikir Islam yakni konsep "tawhìd" yang lebih ditonjolkan, akan tetapi kita tidak bisa menghindar dari realita yang ada, bahwa sains berkembang dan diakui di seluruh dunia ini adalah produk dari Barat. Sederhananya, lihat saja penemu lampu pijar Thomas Alfa Edison, yang karena hasil temuan ilmiahnya bisa menyinari bumi di malam hari, lihat juga penemu alat komunikasi Alexander Graham Bell, sehingga kita bisa berkomunikasi dengan orang meski dengan jarak jauh. Contoh kedua orang tersebut adalah orang non Muslim, tepatnya orang Barat, dan masih banyak daftar orang-orang yang berjasa kepada ilmu pengetahuan lainnya.

Kontribusi pemikiran Sardar tentang sains Islam terhadap ilmu pengetahuan melalui konsep sepuluh parameter sains Islam, menyuruh kita untuk bersama-sama menjaga kelestarian alam, lingkungan dan kehidupan manusia di masa yang akan datang. Menjaga keharmonisan bumi dan manusia agar manusia tidak otoriter dengan sains yang dimilikinya, agar ilmu pengetahuan eksis bukan untuk mendominasi alam dan lingkungan tapi untuk kestabilan hidup manusia di muka bumi.

Zainal Abidin Bagir dalam pengantarnya di buku Barbour, Juru Bicara Tuhan mengatakan bahwa Abdus Salam mengkritik gagasan islamisasi sains yang di dukung oleh Seyyed Husein Nasr dan Ziauddin Sardar. Menurut Salam, gagasan islamisasi sains tidak realistik sama sekali karena membayangkan adanya sistem sains yang baru, yang kerap disebut sebagai pendukung gagasan "khas Islam"-sebagai salah satu wajah fundamentalisme-yang akhir-akhir ini semakin tidak populer karena mengklaim sebagai sains yang inklusif. Bahkan Salam sendiri menganggap bahwa gagasan ini telah mengakibatkan kerugian besar bagi kaum Muslim, yang pada kondisi sekarang ini sedang membutuhkan pengentasan ketertinggalan ilmiahnya. ${ }^{25}$

Tidak hanya Abdus Salam yang mengkritik gagasan islamisasi sains, Pervez Hoodbhoy juga mengkritik gagasan sains dalam Islam, menurutnya ${ }^{26}$ Sains Islam tidak lain adalah pemakaian kata sains secara keliru, mereka yang menggunakan kata sains Islami berusaha melakukan tut wuri handayani kepada

\footnotetext{
25Ian G. Barbour, Juru Bicara Tuhan: Antara Sains dan Agama, terj. E.R. Muhammad, (Bandung: Mizan, 2002), h. 31.

26Pervez Hoodbhoy, Islam dan Sains ..., h. 188-189.
} 
sains yang dipraktekkan oleh kaum Muslimin masa awal, tetapi mereka tidak memiliki kualitas yang menyebabkan mereka melakukan pencapaian para ilmuwan zaman keemasan Islam. jikalau mereka masih hidup di zaman sekarang ini, mungkin para cendekiawan klasik seperti; Ibn Sina, Omar Khayyam, Ibn al-Haytsam dan lain-lain merasa sangat malu melihat apa yang disebut sebagai sains Islami. Para cendekiawan ini, selain menjadi Muslim yang berkepedulian tinggi terhadap agamanya, mempraktekkan sains yang pada dasarnya sekuler, mereka tidak berusaha menemukan rumus matematik untuk mengukur kemunafikan atau pahala. Alih-alih, mereka menemukan teori-teori fisika yang penting dan konsep-konsep baru. Dewasa ini, kita mengingat Nasiruddin Thusi melalui trigonometrinya, Omar Khayyam melalui persamaan pangkat tiganya, Jabir ibn Hayyan melalui aparatus kimianya, al-Jazari melalui mesin-mesinnya yang canggih, dan lain-lain. Mereka semua berurusan dengan realitas, itulah mengapa tempat mereka dalam sejarah dunia tidak goyah, dan mengapa ortodoksi hingga kini tidak memaafkan mereka dan mengecam mereka sebagai pembuat bid'ah dan kafir. Adalah fakta yang hampir dilupakan dewasa ini bahwa pahlawan-pahlawan peradaban Muslim ini seringkali diancam bukan oleh orang kafir atau pasukan Mongol, melainkan oleh kaum atau ummat Muslim ortodoks yang anti-sains yang bersikap sangat tidak ramah.

\section{F. Kesimpulan}

Sardar memulai gagasan sains Islam dengan mengkritik sains Barat yang netral dan bebas nilai, karena sains Barat memarginalkan sisi metafisika dan teologi sehingga sains Barat menimbulkan sifat materialistis bagi manusia, kerusakan ekologi, dan ketidakharmonisan antara alam dan manusia. Oleh sebab itulah, Sardar memberikan gagasan sains Islam yang berfondasi pada nilai-nilai Islam yakni al-Qur'an dan Hadits.

Dengan adanya gagasan Sardar tentang sain Islam yang bertumpu pada alQur'an dan Hadits. Bukan berarti Sardar menolak sains modern, akan tetapi Sardar memberikan parameter-parameter sains dengan berdasarkan pada nilai-nilai Islam. Meskipun sains Barat telah ada, tapi jika salah satu parameterparameter sains Islam terkandung di dalamnya, maka sains Barat tersebut termasuk sains Islam. Adapun parameter-parameter sains Islam menurut Sardar adalah tawhïd (keesaaan Allah), khalīfah (wali Allah), 'ibädah, 'ilm (pe- 
ngetahuan), halāl (hal-hal yang dibolehkan), harām (hal-hal yang dilarang), 'adl (keadilan sosial), zulm (tirani), istiṣlāh (kepentingan umum), dan diya ${ }^{\prime}$ (pemborosan). [w] 


\section{BIBLIOGRAPHY}

Bakar, Osman, Tauhid dan Sains: Esai-esai tentang Sejarah dan Filsafat Sains Islam (Tauhid and Science: Essays on History and Philosophy of Islamic Science), translated by Yuliani Liputo, Bandung: Pustaka Hidayah, 1994.

Barbour, Ian G. Juru Bicara Tuhan: Antara Sains dan Agama (God Speaker: Between Science and Religion), translated by E.R. Muhammad, Bandung: Mizan, 2002.

Departemen Agama RI, al-Qur'an dan Terjemahnya (al-Qur'an and Its Translation), Bandung: Syaamila Cipta Media, 2005.

Golshani, Mehdi, Filsafat Sains Menurut al-Qur'an (Philosophy of Science According to Al-Qur'an), translated by Agus Effendi, Bandung: Mizan, 2003.

Hoodbhoy, Pervez, Islam dan Sains: Pertarungan Menegakkan Rasionalitas (Islam and Science: a Fight to Raise Rationalism), translated by Luqman, Bandung: Pustaka, 1997.

Mahzar, Armahedi, Revolusi Integralisme Islam: Merumuskan Paradigma Sains dan Teknologi Islami (Revolution of Islam Integration: Formulating the Paradigm of Islamic Science and Technology), Bandung: Mizan, 2004.

Rusli, "Islam dan Lingkungan Hidup: Meneropong Pemikiran Ziauddin Sardar" (Islam and Environment: Observing the Thought of Ziauddin Sardar), Majalah Hermenia, Pasca UIN Sunan Kalijaga, Vol. 3. No. 2, July-December 2004.

Sardar, Ziauddin, Exploration in Islamic Sciense, London: Mansel Publishing Limited, 1989.

Sardar, Ziauddin, Jihad Intelektual: Merumuskan Parameter-parameter Sains Islam (Intellectual Jihad: Formulating Parameters of Islamic Science), Surabaya: Risalah Gusti, n.d.

Sardar, Ziauddin, Masa Depan Islam (Future of Islam), translated by Rahmani Astuti, Bandung: Pustaka, 1987.

Sardar, Ziauddin, Sains, Teknologi, dan Pembangunan di Dunia Islam (Science, Technology and Development of Islamic World), translated by Rahmani Astuti, Bandung: Mizan, 1989.

Walisongo, Volume 23, Nomor 2, November 2015 
Syamsuddin, Ach. Maimun, Integrasi Multidimensi Agama dan Sains: Analisis Sains Islam al-Attas dan Mehdi Golshani (Multidimentional Integration of Religion and Science: Analysis of Science Islam in al-Attas and Mehdi Golshani Thought), Yogyakarta: IRCiSod, 2012.

\section{Internet:}

Abdurrahman, Ode, "Sardar dan Rekonstruksi Peradaban Muslim (Sardar and Reconstruction of Moslem Civilization", in http://infolepas. blogspot.com/ 2006/05/sardar-dan-rekonstruksi-peradaban.html, accessed on August 10th, 2015.

Editors Team, "Biography", http://ziauddinsardar.com/ziauddin-sardarbiography/, accessed on August 10th, 2015. 